\title{
Comparison of drug-eluting and bare metal stents for extracranial vertebral artery stenting
}

\author{
Damian R. Maciejewski ${ }^{1}$, Piotr Pieniazek ${ }^{1,2,3}$, Lukasz Tekieli ${ }^{1}$, Piotr Paluszek2 ${ }^{2}$, Tadeusz Przewlocki ${ }^{1,2,3}$, \\ Tomasz Tomaszewski ${ }^{4}$, Roman Machnik ${ }^{2}$, Mariusz Trystula ${ }^{2}$, Jacek Legutko ${ }^{1}$, Anna Kablak-Ziembicka ${ }^{1}$ \\ ${ }^{1}$ Department of Interventional Cardiology, Institute of Cardiology, Jagiellonian University Medical College, John Paul II Hospital, Krakow, \\ Poland \\ 2Department of Vascular Surgery and Endovascular Interventions, John Paul II Hospital, Krakow, Poland \\ ${ }^{3}$ Department of Cardiac and Vascular Diseases, Jagiellonian University, John Paul II Hospital, Krakow, Poland \\ ${ }^{4}$ Department of Neurology and Stroke Unit, John Paul II Hospital, Krakow, Poland
}

Adv Interv Cardiol 2019; 15, 3 (57): 328-337

DOI: https://doi.org/10.5114/aic.2019.87887

\begin{abstract}
A bstract
Introduction: Drug-eluting stents of the first (DES I) and second generation (DES II) proved superior to bare metal stents (BMS) in the coronary territory. However, there are limited data on whether they have any advantage over BMS in vertebral artery stenosis (VAS).

Aim: To compare outcomes of DES (DES I, DES II) and BMS in the treatment of symptomatic extracranial VAS.

Material and methods: During 13-year study period (2003-2016), 392 consecutive patients underwent VAS angioplasty in 428 arteries, including implantation of 148 DES (DES I: 21; DES II: 127 lesions), and 280 BMS.

Results: The technical success rates for DES and BMS groups were $96.7 \%$ and $94.6 \%(p=0.103)$, with similar periprocedural complication rates ( $1.4 \%$ vs. $2.2 \% ; p=0.565)$. VAS degree was reduced from $86 \pm 9.7$ to $2.7 \pm 5.0 \%$ in DES $(p<0.001)$ and from 84.1 \pm 9.4 to $4.3 \pm 6.9 \%$ in BMS $(p<0.001)$. Angiography confirmed in-stent restenosis/occlusion (ISR/ISO) $50-99 \%$ in 53 (14.2\%) and $21(5.6 \%)$ out of 373 patients (409 arteries) with at least 6 -month follow-up. ISR/ISO rates were similar in DES vs. BMS (22.8\% vs. $19.4 \% ; p=0.635)$, as well as in DES I vs. DES II $(6 / 19 ; 31.6 \%$ vs. $25 / 92 ; 27.2 \%, p=0.325)$. Stainless steel $(24 / 135 ; 17.8 \%)$ and cobalt-chromium (23/121;19\%) BMS had significantly lower incidence of ISR/ISO, as compared to platinum-chromium (7/18; 38.9\%), $p=0.034$. ISR/ISO was associated with age $(p=0.01)$ and CRP level $>5 \mathrm{mg} / \mathrm{l}(p=0.043)$, while greater stent length was associated with ISR only in the DES group $(p=0.024)$.

Conclusions: Our results do not support significant differences in ISR/ISO rates between DES and BMS, although differences between particular stent types and ISR rates require further investigation.
\end{abstract}

Key words: drug-eluting stent, in-stent restenosis, bare metal stent, vertebral artery stenting.

Su m m a ry

To date, in contrast to the coronary territory, there are few data regarding comparison of drug-eluting stents (DES) and bare metal stents (BMS) in vertebral artery stenosis (VAS). In our study, we compared DES (first and second generation) and BMS in the treatment of symptomatic extracranial VAS during a 13-year period. The results do not support significant differences in in-stent restenosis/in-stent occlusion (ISR/ISO) rates between DES and BMS in the long-term follow-up, although differences between particular stent types and ISR rates require further investigation.

\section{Introduction}

The origin and the $\mathrm{V} 1$ segment of the vertebral artery (VA) are a common site for atherosclerotic occlusive disease, and they constitute the second most frequent atherosclerosis involvement in the territory of the large supra-aortic arteries, just behind the internal carotid artery location [1-3]. VA lesions lead to signs and symptoms of posterior fossa ischemia (PFI), with significant morbidity and mortality, which may be as high as $30 \%$ [4].

\section{Corresponding author:}

Damian R. Maciejewski, Department of Interventional Cardiology, Institute of Cardiology, Jagiellonian University Medical College, John Paul II Hospital, 80 Pradnicka St, 31-202 Krakow, Poland, phone: +48 609448 745, e-mail: damianmaciejewski@tlen.pl Received: 4.03.2019, accepted: 1.07.2019. 
Of note, one-quarter of ischemic strokes are located in the vertebra-basilar territory (VBT) and around $20 \%$ of posterior circulation strokes occur in the setting of extracranial vertebral artery stenosis (VAS) [2]. In addition, patients experiencing VBT transient ischemic attacks (TIAs) have a $25 \%$ to $35 \%$ risk of stroke within 5 years [5].

The optimal therapeutic management of extracranial VAS is debatable [5]. Three potential methods of treatment are available, medical therapy, surgical reconstruction, and endovascular interventions, but no clear indications have been established [3]. Medical treatment with antiplatelet agents and vasodilators is widely accepted in patients with symptomatic VAS [6].

If symptoms persist, invasive methods of treatment can be used [3]. Open vascular surgery includes endarterectomy, surgical bypass, and carotid-vertebral transposition in referential centers with satisfactory results have been reported [6]. However, with the increasing development of endovascular device technology, percutaneous angioplasty of VAS has become an alternative option to surgery $[3,7]$, with provisional stent implantation that favors the short- and long-term outcome in comparison to balloon angioplasty alone [8].

The real milestone of endovascular interventions was introduction of drug-eluting stents (DES), initially the first (DES I), and then the second generation (DES II), which in the coronary territory were found superior to bare metal stents (BMS) $[9,10]$. However, there are limited data indicating whether DES I and DES II have any advantage over BMS in the posterior circulation territory, namely VAS.

\section{Aim}

Therefore, the main objective of the present study was to evaluate the immediate and long-term outcome of endovascular VAS procedures performed at our institution between 2003 and 2016 in respect of safety and long-term efficacy with special regard to different stent types used. Also, we aimed to identify potential risk factors associated with stenosis recurrence (stent patency).

\section{Material and methods}

The registry is a consecutive series of patients with signs and symptoms of PFI seen at our institution, in whom stent-supported angioplasty was performed during a 13-year period (between the years 2003 and 2016). Written informed consent was obtained from all patients and the study was approved by the local ethics committee, and the study was conducted in compliance with the Declaration of Helsinki.

Of the 392 consecutive patients in the registry, 428 endovascular procedures with stent implantation were performed for V0-V1 segment lesions.

Group I comprised 280 lesions covered with BMS in 270 patients $(195 ; 72.2 \%$ male), with the mean age of $67.5 \pm 8.6$ years.
Group II comprised 148 lesions covered with DES in 144 patients $(98 ; 68.1 \%$ male), with the mean age of $66.6 \pm 8.5$ years. Group II was additionally subdivided into subgroups of patients who had DES I (21 lesions) and DES II implantation (127 lesions).

Detailed study groups characteristics, as well as indications for the endovascular treatment, are presented in Table I. In brief, inclusion criteria for revascularization were either symptomatic patients with at least $60 \%$ lumen diameter stenosis or patients who underwent endovascular treatment of symptomatic subclavian artery disease complicated by a plaque shift with subsequent significant flow limitation in the vertebral artery requiring VA stenting. All patients underwent neurological examination by a site neurologist prior to VA stenting procedure, and re-assessment before hospital discharge. Collected information included demographics, risk factors, clinical description of symptoms, neurologic deficits, and results of diagnostic testing.

\section{Endovascular procedure}

One day before the procedure, patients received a $300 \mathrm{mg}$ loading dose of clopidogrel, followed by $75 \mathrm{mg}$ o.d. for 1 month after BMS and 6-12 months after DES implantation. Patients were on aspirin $75 \mathrm{mg}$ o.d., which was continued indefinitely afterwards.

Access to VA was obtained through a femoral or radial approach with a 6 Fr sheath, as determined by the patient's anatomy. During VA stenting procedures all patients were monitored for vital parameters and neurologically.

After the artery cannulation, heparin was given to achieve an activated coagulation time of 250 to $300 \mathrm{~s}$. Over a 0.035 -inch diagnostic wire a 6 Fr guiding catheter was advanced toward the VA ostium. Then the lesion was crossed with a 0.014 inch coronary guide wire. All VA stenting procedures were unprotected. Direct stenting was performed when possible and the stent type was within the individual responsibility of each interventionist (Figures $1 \mathrm{~A}-\mathrm{C}$ ). The old-generation DES cohort included sirolimus $(n=14)$ and paclitaxel $(n=7)$ eluting stents and the second-generation DES group included everolimus $(n=57)$, biolimus $(n=35)$ and zotarolimus $(n=36)$ eluting stents (Table II). BMS included cobalt-chromium $(n=123)$, stainless steel $(n=139)$ and platinum-chromium $(n=18)$.

Before and after stent deployment, the degree of stenosis was calculated with quantitative angiography. Technical success was defined as post-interventional residual stenosis $<30 \%$

\section{Patients' follow-up}

Clinical performance and complications within 30 days, in-stent restenosis/occlusion (ISR/ISO) and overall survival were compared between DES and BMS groups. Clinical success was defined as technical success with 
Table I. Patient baseline characteristics and indications for treatment

\begin{tabular}{|c|c|c|c|}
\hline Parameter & $\begin{array}{c}\text { DES } \\
(n=144)\end{array}$ & $\begin{array}{c}\text { BMS } \\
(n=270)\end{array}$ & $P$-value \\
\hline \multicolumn{4}{|l|}{ Demography: } \\
\hline Age [years] & $66.6 \pm 8.5$ & $67.5 \pm 8.6$ & 0.080 \\
\hline Men, $n(\%)$ & $98(68.1)$ & $195(72.2)$ & 0.375 \\
\hline \multicolumn{4}{|l|}{ Comorbidities, $n$ (\%): } \\
\hline Coronary artery disease & $89(61.8)$ & $149(55.2)$ & 0.194 \\
\hline Previous myocardial infarction & $41(28.5)$ & $72(26.7)$ & 0.694 \\
\hline Previous percutaneous coronary intervention & $43(29.9)$ & $69(25.6)$ & 0.348 \\
\hline History of coronary artery bypass grafting & $15(10.4)$ & $36(13.3)$ & 0.389 \\
\hline Previous carotid artery stenting & $34(23.6)$ & $56(20.7)$ & 0.500 \\
\hline Carotid artery occlusion & $32(22.2)$ & $73(27)$ & 0.284 \\
\hline $\begin{array}{l}\text { Previous percutaneous transluminal angioplasty in peripheral vascular } \\
\text { disease }\end{array}$ & $6(4.2)$ & $17(6.3)$ & 0.367 \\
\hline Previous carotid endarterectomy & $8(5.6)$ & $7(2.6)$ & 0.124 \\
\hline Hypertension & $138(95.8)$ & $268(99.3)$ & 0.016 \\
\hline Dyslipidaemia & $133(92.4)$ & $264(97.8)$ & 0.008 \\
\hline Diabetes mellitus & $45(31.3)$ & $69(25.6)$ & 0.217 \\
\hline Insulin therapy & $15(10.4)$ & $26(9.6)$ & 0.798 \\
\hline Symptomatic peripheral artery disease & $32(22.2)$ & $53(19.6)$ & 0.533 \\
\hline \multicolumn{4}{|l|}{ Indications for treatment, $n$ (\%): } \\
\hline Vertigo, dizziness & $136(94.4)$ & $252(93.3)$ & 0.657 \\
\hline VBS stroke & $65(45.1)$ & $114(42.2)$ & 0.568 \\
\hline VBS TIA & $35(24.3)$ & $65(24.1)$ & 0.958 \\
\hline Occipital lobe stroke & $15(10.4)$ & $26(9.6)$ & 0.798 \\
\hline Recurrent syncope & $25(17.4)$ & $55(20.4)$ & 0.460 \\
\hline Tinnitus & $1(0.7)$ & $4(1.5)$ & 0.485 \\
\hline
\end{tabular}

Continuous data are presented as the mean \pm standard deviation; categorical data are given as the count (percentage).

resolution of vertebro-basilar insufficiency (VBI) symptoms.

Vascular imaging included carotid and vertebral artery duplex ultrasonography (DUS) or computed tomography angiography (CTA) in all patients performed before discharge, at 6 and 12 months, and then every year on outpatient visits, and conventional angiography if restenosis was suspected.

Repeated angiography was performed if in-stent restenosis/in-stent occlusion (ISR/ISO) was suspected on a noninvasive image combined with the presence of recurrent symptoms. In-stent restenosis was defined as a diameter stenosis $\geq 50 \%$ in the stented artery (Figures $1 \mathrm{D}-\mathrm{G})$.

Incidence rates of major adverse cerebral and coronary event (MACCE), cardiovascular death or any death were recorded during the follow-up period. Data on MACCE were collected during the ultrasound visits. The final closing visit was done through telephone contact with a patient or an appointed family member. For patients lost to follow-up, the data on whether the patients were alive were obtained from the national health registry.

\section{Statistical analysis}

Comparisons between groups was made with Student's $t$-test, one-way analysis of variance or the $\chi^{2}$ test as appropriate.

Continuous variables are presented as the mean \pm standard deviation, and categorical variables are expressed as the counts (percentages). Survival analysis included Kaplan-Meier plots, and comparison of survival in two or more samples was made for events. 

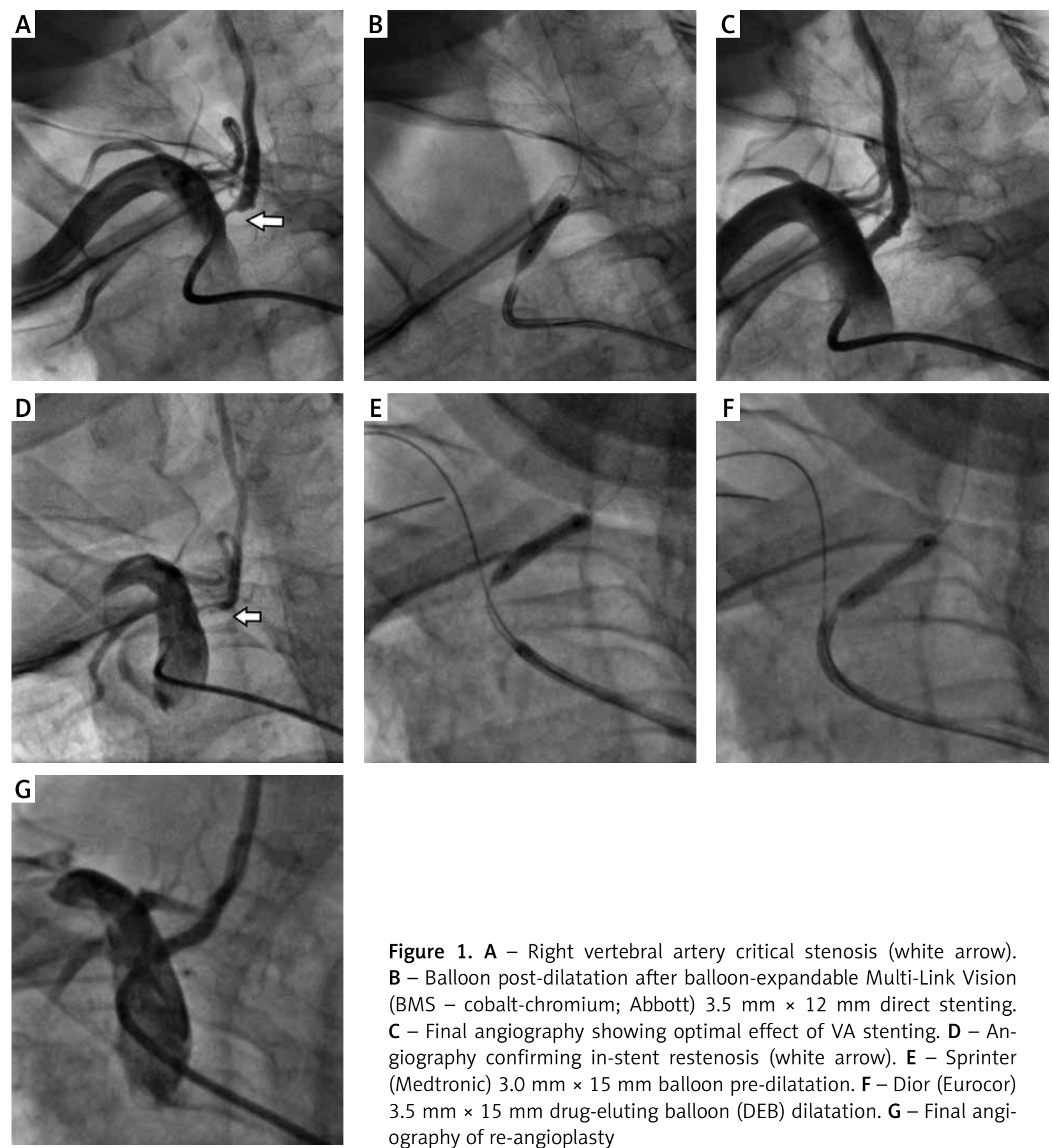

Figure 1. A - Right vertebral artery critical stenosis (white arrow). B - Balloon post-dilatation after balloon-expandable Multi-Link Vision (BMS - cobalt-chromium; Abbott) $3.5 \mathrm{~mm} \times 12 \mathrm{~mm}$ direct stenting. C - Final angiography showing optimal effect of VA stenting. D - Angiography confirming in-stent restenosis (white arrow). E - Sprinter (Medtronic) $3.0 \mathrm{~mm} \times 15 \mathrm{~mm}$ balloon pre-dilatation. F-Dior (Eurocor) $3.5 \mathrm{~mm} \times 15 \mathrm{~mm}$ drug-eluting balloon (DEB) dilatation. G - Final angiography of re-angioplasty

Data were analyzed in two groups: DES vs. BMS or DES I vs. DES II vs. BMS.

The potential independent prognostic markers of ISR during the follow-up period were established from the 10 variables with a univariate analysis. In the case of $p<0.1$ they were entered into a multivariate Cox proportional hazard analysis model. The results of the multivariate logistic regression analysis were expressed as the hazard ratio $(\mathrm{HR})$ and $95 \%$ confidence interval $(95 \% \mathrm{Cl})$.

Statistica version 12 (StatSoft Poland) was used to analyze data. $P$-value $<0.05$ was considered statistically significant.

\section{Results}

In the study period between April 2003 and January 2016, 392 consecutive patients underwent VA stenting in 428 arteries, including implantation of DES in 144 patients, and BMS in 270 patients.

Subjects in the BMS group, as compared to DES group, had higher prevalence of hypertension $(p=0.016)$ and hyperlipidemia $(p=0.008)$, whereas there were no significant differences with respect to the cardiovascular history and atherosclerosis risk factors as well as symptoms of PFI. The detailed clinical characteristics are summarized in Table I. 
Table II. Procedural data and stent type

\begin{tabular}{|c|c|c|c|}
\hline Parameter & $\begin{array}{c}\text { DES } \\
(n=148)\end{array}$ & $\begin{array}{c}\text { BMS } \\
(n=280)\end{array}$ & $P$-value \\
\hline Right VA, $n(\%)$ & $79(53.4)$ & $118(42.1)$ & 0.037 \\
\hline Left VA, $n(\%)$ & $71(48)$ & $162(57.9)$ & \\
\hline Transradial approach, $n$ (\%) & $10(6.8)$ & $16(5.9)$ & 0.668 \\
\hline Contralateral VA occlusion, $n(\%)$ & $13 / 140(9.3)$ & $23 / 260(8.9)$ & 0.884 \\
\hline V0/V1 segment, $n$ & 148 & 275 & 0.041 \\
\hline \multicolumn{4}{|l|}{ Old generation DES, $n$ (\% of DES): } \\
\hline Sirolimus-eluting stent & $14(9.4)$ & $\mathrm{n} / \mathrm{a}$ & \\
\hline Paclitaxel-eluting stent & $8(5.3)$ & $n / a$ & \\
\hline \multicolumn{4}{|l|}{ Second generation DES, $n$ (\% of DES): } \\
\hline Everolimus-eluting stent & $57(38)$ & $n / a$ & \\
\hline Biolimus-eluting stent & $35(23.3)$ & $n / a$ & \\
\hline Zotarolimus-eluting stent & $36(24)$ & $n / a$ & \\
\hline Stainless-steel, $n$ (\%) & $n / a$ & $139(49.6)$ & \\
\hline Cobalt-chromium, $n(\%)$ & $n / a$ & $123(44)$ & \\
\hline Platinum-chromium, $n$ (\%) & $n / a$ & $18(6.4)$ & \\
\hline \multicolumn{4}{|l|}{ Stenosis severity - angio (\%): } \\
\hline Pre-treatment, mean \pm SD & $86.0 \pm 9.7$ & $84.1 \pm 9.4$ & 0.056 \\
\hline Post-treatment, mean \pm SD & $2.7 \pm 5$ & $4.3 \pm 6.9$ & 0.014 \\
\hline Stent diameter, mean $\pm \mathrm{SD}[\mathrm{mm}]$ & $3.4 \pm 0.5$ & $4.2 \pm 0.8$ & $<0.001$ \\
\hline Stent length, mean $\pm \mathrm{SD}[\mathrm{mm}]$ & $12 \pm 3.9$ & $11.9 \pm 2.7$ & 0.323 \\
\hline Direct stenting, $n(\%)$ & $110(73.3)$ & $221(78.9)$ & 0.279 \\
\hline Maximum inflation pressure, mean \pm SD [atm] & $11.6 \pm 2.4$ & $11.7 \pm 2.4$ & 0.265 \\
\hline Maximum post-dilatation balloon pressure, mean \pm SD [atm] & $16.7 \pm 3.2$ & $16.2 \pm 3.2$ & 0.056 \\
\hline Simultaneous VAS + SAS, $n(\%)$ & $6(4)$ & $9(6.1)$ & 0.653 \\
\hline
\end{tabular}

Two stents implanted to cover one lesion. Continuous data are presented as the mean \pm standard deviation; categorical data are given as the count and percentage. VAS + SAS - vertebral and subclavian artery stenting.

In 36 (9.2\%) patients bilateral VA stenting was performed, whereas in the remaining 2 patients, 2 stents to V0 and V1 segments of the same artery were implanted. In all cases of double stenting, the DES was used. There were no patients with isolated VA take-off from the aortic arch.

Fifteen (3.8\%) patients underwent endovascular treatment of symptomatic subclavian artery disease on the same session, including 2 patients with significant symptomatic plaque shift causing obstruction of the VA origin.

Detailed study procedure technique and stent types are presented in Table II. In brief, the stenosis degree was reduced from $86 \pm 9.7$ to $2.7 \pm 5.0 \%$ in the DES group and from $84.1 \pm 9.4$ to $4.3 \pm 6.9 \%$ in the BMS group ( $p<0.001$ ). The technical success rate was $96.7 \%$ for DES and $94.6 \%$ for BMS group $(p=0.103)$. The PFI symptoms resolved in $90.3 \%$ and $92.2 \%$ of patients in the DES and BMS cohort, respectively ( $p=0.739$ ).

Periprocedural complications occurred in 2 (1.4\%) and $6(2.2 \%)$ subjects in the DES and the BMS group respectively $(p=0.565)$, and they included one hematoma requiring transfusion and one non-flow limiting dissection in the DES group, and 3 TIAs, one hematoma with transfusion, one non-flow limiting dissection and one dissection requiring additional stent implantation in the BMS group. There were no ischemic strokes, myocardial infarction (MI) or any death within 30 days in either group.

MACCE and any death were analyzed during the median follow-up period of 45.4 months (range: 1-144 months) in the DES group and 59 months (range: 1-150 months) 
in the BMS group $(p<0.001)$. The observation was completed for 362 (92.3\%) patients at the final outpatient follow-up visit, while 30 (7.7\%) patients (24 in BMS and 6 in DES) were lost to follow-up. As per records of the General Electronic Population Register by the Ministry of Interior and Administration Database, 18 out of the 30 'lost-to-follow-up' patients (16 in BMS and 2 in DES group) died.

Overall, there were 56 (14.3\%) deaths. Out of 362 patients, acute $\mathrm{MI}$ was recorded in 16 (4.4\%), while an ischemic cerebral event occurred in $10(2.8 \%)$ patients (2 in DES and 8 in BMS group), including 9 with a probable relation to the VA stenting territory, whereas 1 was due to new onset atrial fibrillation. Vertigo, dizziness and syncope recurrence were noted in 41 (11.3\%) patients.

Renal impairment (elevated creatinine level > upper limit norm (ULN)) was related to higher mortality (Figure 2 A). No difference was detected in survival curves related to $\mathrm{MI}$ and stroke between DES vs. BMS cohorts (Figure 2 B). However, the all-cause mortality was the highest for patients in whom the old-generation DES was implanted (Figure $2 \mathrm{C}$ ).

In 373 patients who completed at least a 6-month follow-up period with DUS/CTA examination, 409 re-

A

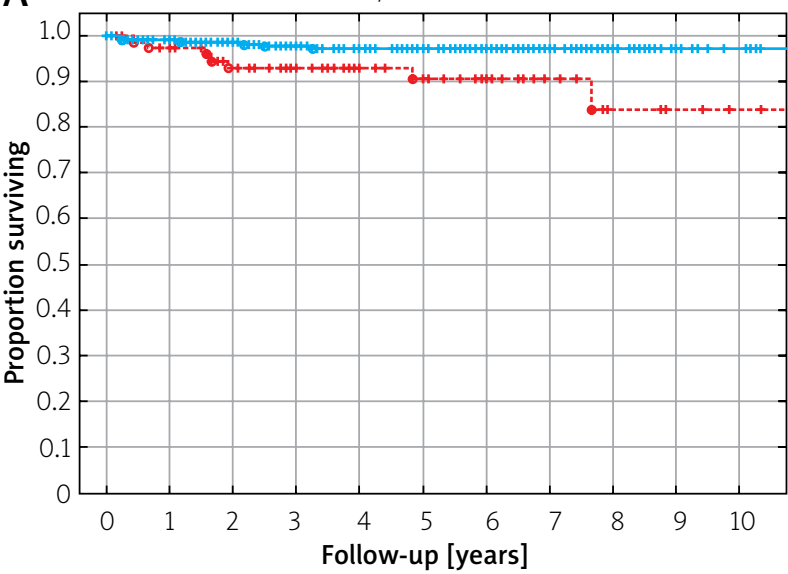

_Creatinine within norm -.---. Creatinine $<$ norm

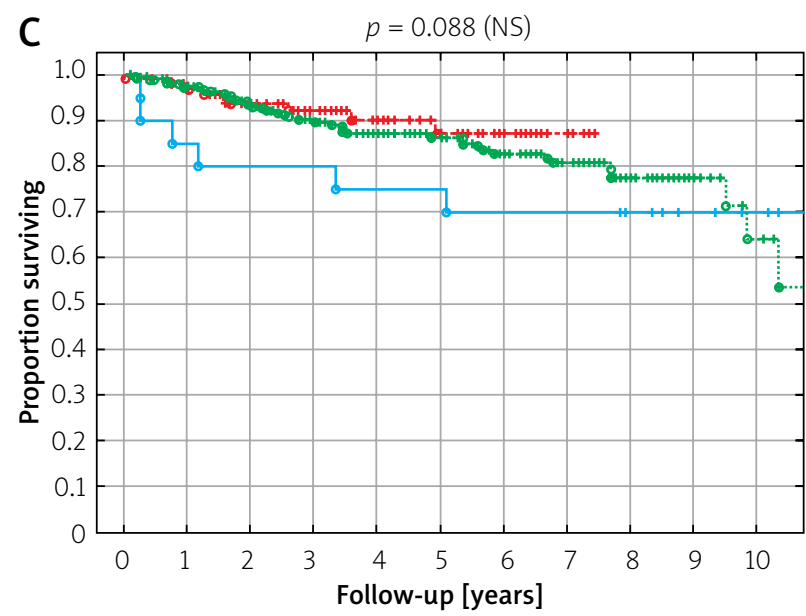

_ DES old generation ..--.. DES second generation ......... BMS vascularized vertebral vessels were subjected to further analysis (Table III). ISR/ISO exceeding 50\% was suspected in $84(22.5 \%)$ patients on DUS, and $16(4.3 \%)$ on CTA. Angiography confirmed ISRs > 50\% in 53 (14.2\%) patients and ISOs in 21 (5.6\%) managed conservatively. All patients with ISR > 70\% underwent subsequent endovascular treatment with either plain balloon angioplasty (14 patients), drug-eluting balloon (22 patients) or DES stent implantation (17 patients).

The overall ISR/ISO rate was $19.8 \%$ with no significant difference between DES and BMS groups (22.8\% vs. $19.4 \% ; p=0.635)$. Out of 19 old-generation DES, $6(31.6 \%)$ ISRs occurred, whereas out of the 92 second-generation DES, there were $25(27.2 \%)$ ISRs ( $p=0.325)$.

Recurrent ISR/ISO was noted in 3 patients, subsequently treated with drug-coated balloon $(n=2)$ and plain balloon angioplasty $(n=1)$.

In the BMS group, long-term patency was obtained significantly more often with stainless steel (24/135, $17.8 \%)$ and cobalt-chromium (23/121, 19\%), as compared to platinum-chromium BMS (7/18, 38.9\%), $p=0.034$.

By contrast, in the DES group, implantation of biolimus stent was associated with the lowest restenosis rate

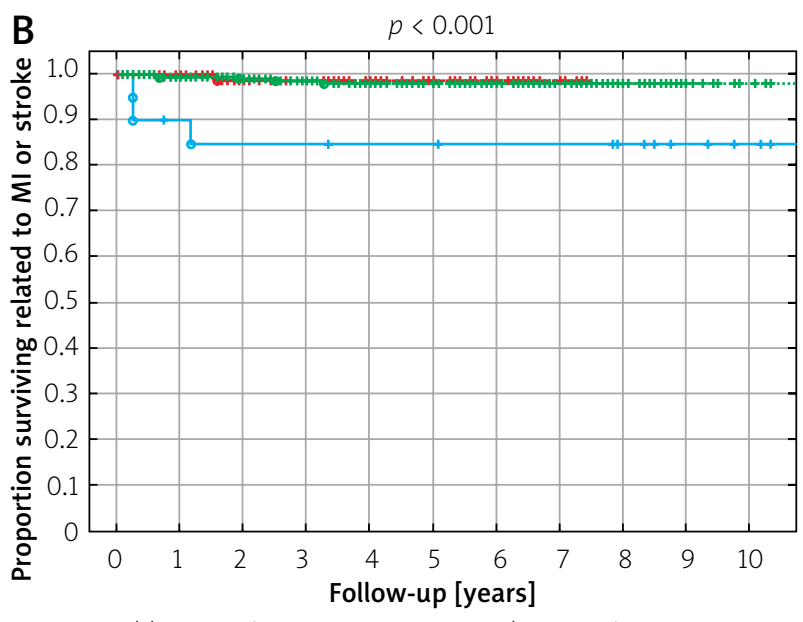

— DES old generation --.-- DES second generation ........ BMS

Figure 2. A - Survival according to the level of creatinine. B - Survival related to $\mathrm{MI}$ or stroke. C - Overall survival curves 
Table III. ISR/ISO and no ISR/ISO analysis

\begin{tabular}{|c|c|c|c|c|c|c|}
\hline \multirow[t]{2}{*}{ Parameter } & \multicolumn{3}{|c|}{ BMS } & \multicolumn{3}{|c|}{ DES } \\
\hline & $\begin{array}{l}\text { ISR/ISO } \\
(n=54)\end{array}$ & $\begin{array}{l}\text { No ISR/ISO } \\
(n=220)\end{array}$ & $P$-value & $\begin{array}{l}\text { ISR/ISO } \\
(n=31)\end{array}$ & $\begin{array}{l}\text { No ISR/ISO } \\
(n=105)\end{array}$ & $P$-value \\
\hline Age [years] & $65 \pm 8$ & $68.2 \pm 8.7$ & 0.012 & $63.4 \pm 8.5$ & $67.1 \pm 8.4$ & 0.013 \\
\hline Men, $n(\%)$ & $36(8.8)$ & $161(39.3)$ & \multirow[t]{2}{*}{0.340} & $23(5.6)$ & $71(17.3)$ & \multirow[t]{2}{*}{0.486} \\
\hline Women, $n(\%)$ & $18(4.4)$ & $59(14.4)$ & & $8(1.9)$ & $34(8.3)$ & \\
\hline $\begin{array}{l}\text { Time to detection of ISR/ISO, } \\
\text { mean } \pm \mathrm{SD} \text { [month] }\end{array}$ & $20.5 \pm 21.3$ & $n / a$ & $\mathrm{n} / \mathrm{a}$ & $15.8 \pm 12$ & $\mathrm{n} / \mathrm{a}$ & 0.228 \\
\hline $\begin{array}{l}\text { C-reactive protein, } \\
\text { mean } \pm \mathrm{SD}[\mathrm{mg} / \mathrm{l}]\end{array}$ & $4.14 \pm 4.2$ & $3.74 \pm 6.59$ & 0.103 & $4.43 \pm 3.07$ & $2.9 \pm 3.41$ & 0.334 \\
\hline $\begin{array}{l}\text { Low-density lipoprotein, } \\
\text { mean } \pm S D[\mathrm{mmol} / 1]\end{array}$ & $2.47 \pm 0.83$ & $2.58 \pm 0.82$ & 0.298 & $2.61 \pm 1.03$ & $2.49 \pm 0.76$ & 0.120 \\
\hline $\begin{array}{l}\text { Creatinine, } \\
\text { mean } \pm \mathrm{SD}[\mu \mathrm{mol} / \mathrm{l}]\end{array}$ & $89.7 \pm 19.5$ & $93 \pm 35.6$ & 0.45 & $90 \pm 24.4$ & $88.6 \pm 23.1$ & 0.94 \\
\hline Glucose, mean \pm SD $[\mathrm{mmol} / \mathrm{l}]$ & $6.03 \pm 1.36$ & $6.04 \pm 1.57$ & 0.088 & $5.44 \pm 0.83$ & $6.19 \pm 2.1$ & 0.59 \\
\hline Diabetes mellitus, $n(\%)$ & $17(31.5)$ & $52(23.6)$ & 0.234 & $6(19.4)$ & $36(34.3)$ & 0.114 \\
\hline Hypertension, $n(\%)$ & $54(100)$ & $208(94.5)$ & 0.265 & $30(96.8)$ & $97(92.4)$ & 0.387 \\
\hline Left vertebral artery, $n$ (\%) & $32^{*}(7.8)$ & $127(31.1)$ & \multirow[t]{2}{*}{0.725} & $16(3.9)$ & $50(12.2)$ & \multirow[t]{2}{*}{0.696} \\
\hline Right vertebral artery, $n(\%)$ & $22^{*}(5.1)$ & $93(22.7)$ & & $15(3.7)$ & $55(13.4)$ & \\
\hline $\begin{array}{l}\text { Stent diameter, } \\
\text { mean } \pm S D[\mathrm{~mm}]\end{array}$ & $4.22 \pm 0.78$ & $4.23 \pm 0.76$ & 0.32 & $3.41 \pm 0.49$ & $3.40 \pm 0.54$ & 0.23 \\
\hline $\begin{array}{l}\text { Stent length, } \\
\text { mean } \pm S D[\mathrm{~mm}]\end{array}$ & $11.8 \pm 2.1$ & $11.9 \pm 2.8$ & 0.72 & $13.5 \pm 3.1$ & $11.6 \pm 4.1$ & 0.024 \\
\hline Biolimus, $n$ & $\mathrm{n} / \mathrm{a}$ & $\mathrm{n} / \mathrm{a}$ & $n / a$ & 4 & 27 & \multirow{5}{*}{$\begin{array}{c}0.159 \\
0.063^{\#}\end{array}$} \\
\hline Everolimus, $n$ & $\mathrm{n} / \mathrm{a}$ & $\mathrm{n} / \mathrm{a}$ & $\mathrm{n} / \mathrm{a}$ & 11 & 41 & \\
\hline Zotarolimus, $n$ & $n / a$ & $n / a$ & $\mathrm{n} / \mathrm{a}$ & 10 & 24 & \\
\hline Paclitaxel, $n$ & $n / a$ & $n / a$ & $\mathrm{n} / \mathrm{a}$ & 3 & 2 & \\
\hline Sirolimus, $n$ & $\mathrm{n} / \mathrm{a}$ & $\mathrm{n} / \mathrm{a}$ & $\mathrm{n} / \mathrm{a}$ & 3 & 11 & \\
\hline Stainless steel, $n$ & 24 & 111 & \multirow{3}{*}{$\begin{array}{c}0.103 \\
0.034^{\star \star}\end{array}$} & $\mathrm{n} / \mathrm{a}$ & $\mathrm{n} / \mathrm{a}$ & $\mathrm{n} / \mathrm{a}$ \\
\hline Cobalt-chromium, $n$ & 23 & 98 & & $\mathrm{n} / \mathrm{a}$ & $\mathrm{n} / \mathrm{a}$ & $n / a$ \\
\hline Platinum-chromium, $n$ & 7 & 11 & & $\mathrm{n} / \mathrm{a}$ & $\mathrm{n} / \mathrm{a}$ & $\mathrm{n} / \mathrm{a}$ \\
\hline
\end{tabular}

${ }^{*}$ One patient with left and right vertebral artery ISR/ISO, ${ }^{* *} p$-value for stainless steel and cobalt-chromium vs platinum-chromium BMS. \#P-value for paclitaxel and zotarolimus vs. other types of DES.

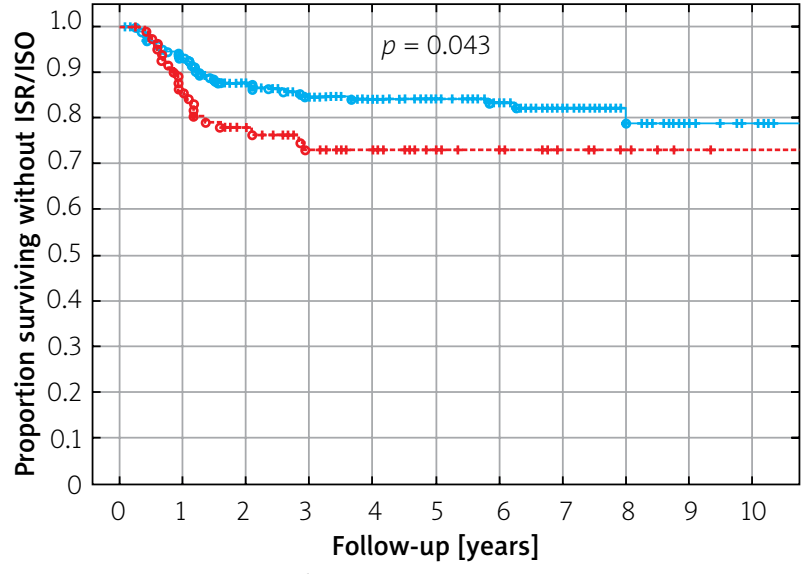

— CRP within norm -..--. CRP > norm

Figure 3. Survival without ISR/ISO according to the level of CRP
(4/31, 12.9\%), as compared to everolimus (11/52, $21.2 \%)$, sirolimus (3/14, 21.4\%), zotarolimus (10/34, 29.4\%) and paclitaxel (3/5,60\%), $p=0.135$.

Among analyzed clinical and procedural parameters (Tables III, IV), younger age was related to ISR risk, both in the BMS $(p=0.012)$ and the DES $(p=0.013)$ group, while greater stent length was associated with ISR only in the DES group ( $p=0.024)$ (Table III). In the survival analysis, elevated $\mathrm{C}$-reactive protein level above $5 \mathrm{mg} / \mathrm{l}$ was significantly associated with ISR/ISO risk $(p=0.041$ ) (Figure 3$)$. In the BMS group, data favored implantation of stainless steel or cobalt chromium BMS over platinum-chromium BMS, while in DES group no independent parameter with the multivariate Cox proportional hazard analysis was identified in terms of ISR (Table IV). 
Table IV. Factors associated with in-stent restenosis identified by univariate and multivariate Cox proportional hazard analysis

\begin{tabular}{lcc} 
Parameter & $\begin{array}{c}\text { Univariate Cox proportional } \\
\text { hazard analysis } \\
\text { HR }(95 \% \text { Cl); } p \text {-level }\end{array}$ & $\begin{array}{c}\text { Multivariate Cox proportional } \\
\text { hazard analysis } \\
\text { HR }(95 \% \text { Cl); } p \text {-level }\end{array}$ \\
\hline Age & $0.96(0.94-0.99) ; 0.002$ & $0.96(0.92-0.99) ; 0.05$ \\
\hline Hyperlipidemia & $0.85(0.27-2.69) ; 0.78$ & - \\
\hline Hypertension & $0.58(0.08-4.15) ; 0.58$ & - \\
\hline Intervention on RVA vs. LVA & $0.92(0.59-1.42) ; 0.69$ & - \\
\hline Stent diameter & $5.58(0.01-17.2) ; 0.912$ & - \\
\hline Stent length & $1.43(0.01-8.28) ; 0.988$ & - \\
\hline CRP & $1.01(0.98-1.04) ; 0.36$ & \\
\hline Stent type: & & \\
\hline \begin{tabular}{l} 
Stainless steel/cobalt chromium vs. platinum-chromium BMS \\
\hline Paclitaxel/zotarolimus vs. biolimus/everolimus DES
\end{tabular} & $0.22(0.10-0.78) ; 0.001$ & $0.28(0.13-0.64) ; 0.002$ \\
\hline
\end{tabular}

\section{Discussion}

Endovascular treatment of vertebral artery origin stenosis greater than $50 \%$, in patients with PFI symptoms that are present despite optimal medical therapy (OMT: risk factor modifications, antiplatelet and statin therapies), is commonly accepted, as recurrence rates of vertebrobasilar territory ischemic strokes are high, especially in the first days and few weeks after the event [11, 12].

In line, stent-supported angioplasty of VAS is encouraged by low or very low periprocedural complication rates of death and ischemic stroke, rarely exceeding $1-1.5 \%$ in large-volume dedicated centers. Our series of 428 cases showed $3(0.7 \%)$ periprocedural TIAs, and no major strokes or deaths. Also, in smaller studies, the perioperative outcomes are good [3, 5]. E.g. in the Vertebral Artery Ischaemia Stenting Trial (VIST) comparing risks and benefits of VAS stenting plus OMT for recently symptomatic VAS with OMT alone, in a group of 48 patients who received stent for extracranial VAS, 1 (2.1\%) patient had a nonfatal stroke within 30 days of intervention, with no deaths [5]. This randomized study showed a non-significantly lower number of fatal and nonfatal stroke or TIA in the proximal VAS stenting plus OMT arm as compared to OMT alone (log rank $p=0.07$ ) [5].

Controversially, the enthusiasm for endovascular treatment of the vertebral artery origin stenosis, in patients refractory to OMT, is somewhat limited by inconsistent reports concerning recurrent stenosis $[3,13]$.

The rate of significant ISR (greater than 50\%) after either BMS or DES is extremely variable in the literature. After BMS use, the ISR rate can reach $48-55 \%$ and when DES are used it can reach 63\% [3, 13-16].

In the Eberhardt et al. review of 300 interventions for proximal VAS, ISR occurred in $26 \%$ of cases after a mean of 12 months (range: 3-25 months) [17]. In this context, our long-term results are good, as the ISR rate was 19.8\% for the whole study group, with no significant differences in crude ISR rates between the BMS and the DES groups.

Nevertheless, recently, a rising number of case series support the use of DES in endovascular treatment of VAS, which relates to the reduced rate of ISR/ISO, as compared to BMS in long-term follow-up [14, 18].

The expectation from DES is a decrease in ISR through inhibition of smooth muscle and endothelial proliferation. Although experience described in the coronary literature largely supports such practice, DES I in cardiac procedures have been found to be associated with clot formation in some cases, resulting in thrombosis at the stent site $[10,19]$. Recently, second generation DES were introduced with the scope to overcome the limitations of the first generation DES.

Consistently, the average ISR rates in patients with VAS were calculated at 29.6\% (range: 3-55\%) from 12 case series with BMS use and at 14.1\% (range: 0-63\%) from 7 case series with DES use [3].

Furthermore, in one reported study, BMS ( $\mathrm{HR}=2.02$; $p<0.05)$ was even independently associated with an increased risk of ISR [20].

Our data indicate large variations between ISR rates and type of the stent implanted within the analyzed subgroups. In the BMS group, we observed significantly higher rates of ISR when a platinum-chromium stent was used (38.9\%), as compared to stainless steel (17.8\%) and cobalt-chromium (19\%) BMS, whereas in the DES group the best outcome was noted for the biolimus stent (12.9\%), everolimus (21.2\%), and sirolimus (21.4\%), as compared to zotarolimus (29.4\%) and paclitaxel (60\%) coated stents.

In contrast, Song et al. found ISR of 20.2\% (19/94) at 1 year for stainless steel and cobalt-chromium BMS, 
compared to $6.3 \%(7 / 112)$ in sirolimus $(n=73)$ and paclitaxel-coated ( $n=52$ ) DES I [21]. The stent type may also matter during the intracranial interventions in the vertebrobasilar territory [22].

In Langwieser's study, the ISR was 23\%, concerning the stent type, self-expandable BMS were associated with a significant higher ISR rate compared to balloon-expandable stents $(p=0.012)$, and although not statistically significant, there was a lower ISR rate in DES compared to BMS $(p=0.068)$ [23].

As most case series with stenting of VAS include patients with either intracranial and extracranial VAS, as well as using different types of stents, data on the relationship between particular stent type and ISR risk are missing or not available [24].

Again, more experience is available in the coronary territory; e.g. a meta-analysis of Navarese et al. showed that everolimus DES reduced the odds of repeat revascularization compared with paclitaxel-eluting stents, but zotarolimus-Endeavor stents increased the odds compared with sirolimus-eluting stents [9].

The major limitation in the DES choice is the former availability of stent diameters present on the market. Most DES suffered from size limitations (up to $4 \mathrm{~mm}$ ), and for that reason we were not able to randomize patients to BMS and DES groups for direct head-to-head comparisons. However, in both our present and a previously reported study, although DES had mean lower diameter as compared to BMS, this fact had no impact on the ISR rates [25].

This issue seems relevant, as some studies indicate that stent diameter is an important indicator of ISR risk $[26,27]$. E.g. in the study of Zhou et al., ISR rates were found to be associated with tortuosity of extracranial VA and lower stent diameter [26]. This is in line with our previous findings concerning carotid and subclavian artery stenosis, where stent diameter along with inflammatory status, and patient age were independently associated with ISR [28-31].

In contrast, in the study of Song et al., stent diameter and length were not associated with ISR risk, but the mean stent diameter was quite large (BMS: $4.4 \pm 0.7 \mathrm{~mm}$ vS. DES I: $4.1 \pm 0.8 \mathrm{~mm})$, whereas diabetes $(H R=2.66$, $p=0.022)$ and smoking $(\mathrm{HR}=3.85, p=0.015)$ predicted the need for repeated revascularization [21]. In our study stainless steel and cobalt chromium BMS was associated with IRS risk reduction as compared to platinum-chromium BMS implantation, while younger patient age and stent length in the DES group increased the risk of ISR/ ISO. In the study by Werner et al. of vertebral artery origin lesions, stent compression/recoil was found by angiography in 11 (39\%) of the patients who received a paclitaxel-eluting stent at a mean follow-up of 16 months, which limited the long-term outcome [32].

The constant development of drugs released by stents and type of material allow better long-term outcomes to be achieved compared to old-generation stents.
One obvious limitation of the study is the lack of patient randomization to the BMS and the DES. However, as the time period of study enrollment is long (since year 2003), DES were not available at the beginning. Later DES of a limited diameter were available (less than $4 \mathrm{~mm}$ in diameter), not suitable for larger vertebral arteries. For that reason a direct head-to-head comparisons between DES and BMS is not possible. We observed differences between stent type and IRS prevalence, but the lack of statistical significance between DES subtypes is probably attributable to the low numbers of some stents.

\section{Conclusions}

Both DES and BMS vertebral artery stenting can be performed safely with high technical success and a low periprocedural complication rate. No significant difference in ISR/ISO between DES and BMS was noted in the long-term follow-up, but in the subgroups analysis paclitaxel DES as well as platinum-chromium BMS had the highest ISR/ISO rates.

\section{Acknowledgments}

We would like to thank Doctor Ewa Wozniakiewicz, who was responsible for statistical analysis.

\section{Conflict of interest}

The authors declare no conflict of interest.

\section{References}

1. Cloud GC, Markus HS. Diagnosis and management of vertebral artery stenosis. QJM 2003; 96: 27-54.

2. Savitz SI, Caplan LR. Vertebrobasilar disease. N Engl J Med 2005; 352: 2618-26.

3. Kocak B, Korkmazer B, Islak C, et al. Endovascular treatment of extracranial vertebral artery stenosis. World J Radiol 2012; 4: 391-400.

4. Wityk RJ, Chang HM, Rosengart A, et al. Proximal extracranial vertebral artery disease in the New England medical center posterior circulation registry. Arch Neurol 1998; 55: 470-8.

5. Markus HS, Larsson SC, Kuker W, et al. Stenting for symptomatic vertebral artery stenosis: the Vertebral Artery Ischaemia Stenting Trial. Neurology 2017; 89: 1229-36.

6. Berguer R, Flynn L, Kline R, et al. Surgical reconstruction of the extracranial vertebral artery: management and outcome. J Vasc Surg 2000; 31: 9-18.

7. Borhanim Haghighi A, Edgell RC, Cruz-Flores S, et al. Vertebral artery origin stenosis and its treatment. J Stroke Cerebrovasc Dis 2011; 20: 369-76.

8. Stayman AN, Nogueira RG, Gupta R. A systematic review of stenting and angioplasty of symptomatic extracranial vertebral artery stenosis. Stroke 2011; 42: 2212-6.

9. Navarese EP, Kowalewski M, Kandzari D, et al. First-generation versus second-generation drug-eluting stents in current clinical practice: updated evidence from a comprehensive metaanalysis of randomised clinical trials comprising 31379 patients. Open Heart 2014; 1: e000064. 
10. Abu Sharar H, Gomes B, Chorianopoulos E, et al. Procedural advantages of a novel coronary stent design with ultra-thin struts and bioabsorbable abluminal polymer coating in an all-comers registry. Adv Interv Cardiol 2018; 14: 240-6.

11. Gulli G, Marquardt L, Rothwell PM, Markus HS. Stroke risk after posterior circulation stroke/transient ischemic attack and its relationship to site of vertebrobasilar stenosis: pooled data analysis from prospective studies. Stroke 2013; 44: 598-604.

12. Aboyans V, Ricco JB, Bartelink MEL, et al. 2017 ESC Guidelines on the Diagnosis and Treatment of Peripheral Arterial Diseases, in collaboration with the European Society for Vascular Surgery (ESVS): document covering atherosclerotic disease of extracranial carotid and vertebral, mesenteric, renal, upper and lower extremity arteries. Endorsed by: the European Stroke Organization (ESO) The Task Force for the Diagnosis and Treatment of Peripheral Arterial Diseases of the European Society of Cardiology (ESC) and of the European Society for Vascular Surgery (ESVS). Eur Heart J 2018; 39: 763-816.

13. Ogilvy CS, Yang X, Natarajan SK, et al. Restenosis rates following vertebral artery origin stenting: does stent type make a difference? J Invasive Cardiol 2010; 22: 119-24.

14. Langwieser N, Buyer D, Schuster T, et al. Bare metal vs. drug-eluting stents for extracranial vertebral artery disease: a meta-analysis of nonrandomized comparative studies. J Endovasc Ther 2014; 21: 683-92.

15. Lugmayr H, Kastner M, Fröhler W, et al. Sirolimus-eluting stents for the treatment of symptomatic extracranial vertebral artery stenoses: early experience and 6-month follow-up. Rofo 2004; 176: 1431-5.

16. Taylor RA, Siddiq F, Suri MF, et al. Risk factors for in-stent restenosis after vertebral ostium stenting. J Endovasc Ther 2008; 15: 203-12.

17. Eberhardt O, Naegele T, Raygrotzki S, et al. Stenting of vertebrobasilar arteries in symptomatic atherosclerotic disease and acute occlusion: case series and review of the literature. J Vasc Surg 2006; 43: 1145-54.

18. Tank H, Ghosh R, Gupta V, et al. Drug eluting stents versus bare metal stents for the treatment of extracranial vertebral artery disease: a meta-analysis. J Neurointerv Surg 2016; 8: 770-4.

19. Gąsior P, Gierlotka M, Szczurek-Katanski K, et al. Safety and efficacy of biodegradable polymer-coated thin strut sirolimus-eluting stent vs. durable polymer-coated everolimus-eluting stent in patients with acute myocardial infarction. Adv Interv Cardiol 2018; 14: 347-55.

20. Che WQ, Dong H, Jiang XJ, et al. Clinical outcomes and influencing factors of in-stent restenosis after stenting for symptomatic stenosis of the vertebral V1 segment. J Vasc Surg 2018; 68: 1406-13.

21. Song L, Li J, Gu Y, et al. Drug-eluting vs. bare metal stents for symptomatic vertebral artery stenosis. J Endovasc Ther 2012; 19: 231-8.

22. He Y, Li T, Bai W, et al. Cerebrovascular drug-eluting stent versus bare-metal stent in the treatment of vertebral artery stenosis: a non-inferiority randomized clinical trial. J Stroke 2019; 21: 101-4.

23. Langwieser N, Prothmann S, Buyer D, et al. Safety and efficacy of different stent types for the endovascular therapy of extracranial vertebral artery disease. Clin Res Cardiol 2014; 103: 353-62.

24. Jenkins JS, Stewart M. Endovascular treatment of vertebral artery stenosis. Prog Cardiovasc 2017; 59: 619-25.
25. Paluszek P, Pieniążek P, Musiałek P, et al. Symptomatic vertebral artery stenting with the use of bare metal and drug eluting stents. Postep Kardiol Interw 2009; 5: 1-6.

26. Zhou Z, Yin Q, Xu G, et al. Influence of vessel size and tortuosity on in-stent restenosis after stent implantation in the vertebral artery ostium. Cardiovasc Intervent Radiol 2011; 34: 481-7.

27. Chen W, Huang F, Li M, et al. Incidence and predictors of the instent restenosis after vertebral artery ostium stenting. J Stroke Cerebrovasc Dis 2018; 27: 3030-5.

28. Tekieli L, Pieniazek P, Musialek P, et al. Zotarolimus-eluting stent for the treatment of recurrent, severe carotid artery in-stent stenosis in the TARGET-CAS population. J Endovasc Ther 2012; 19: 316-24.

29. Gacoń J, Przewłocki T, Podolec J, et al. Prospective study on the prognostic value of repeated carotid intima-media thickness assessment in patients with coronary and extra coronary steno-occlusive arterial disease. Pol Arch Intern Med 2019; 129: 12-21.

30. Przewlocki T, Wrotniak L, Kablak-Ziembicka A et al. Determinants of long-term outcome in patients after percutaneous stent-assisted management of symptomatic subclavian or innominate artery stenosis or occlusion. Eurolntervention 2017; 13: $1355-64$.

31. Maciejewski D, Tekieli $Ł$, Kabłak-Ziembicka A, et al. Transradial approach for vertebral artery stenting. Postep Kardiol Interw 2015; 11: 32-6.

32. Werner M, Braunlich S, Ulrich M, et al. Drug eluting stents for the treatment of vertebral artery origin stenosis. J Endovasc Ther 2010; 17: 232-40. 